\title{
Alcalde mayor de alzadas en el ayuntamiento de Toledo
}

\author{
Ángel Santos Vaquero \\ Doctor en Historia Moderna
}

RESUMEN:

Los municipios del territorio peninsular cristiano, en un principio autónomos, irán viendo cómo sus ma-

gistraturas serán dominadas, a partir del siglo XIII, por las oligarquías aristocráticas y alta burguesía, que se reservarán dichos cargos y monopolizarán su gobierno. Posteriormente serán los monarcas los que tratarán de controlar estos cabildos, aprovechando cualquier coyuntura favorable para uniformar-

los en su ordenamiento jurídico bajo el Derecho Romano, en detrimento de la competencia judicial de los alcaldes y de los fueros locales. Para ello crearán una serie de instituciones (corregidor, regidores, alcaldes de alzadas, merinos...) sobre las que se arrogarán el derecho de nombramiento. Estos cargos de delegación regia recaerán en unas familias determinadas pertenecientes a la aita nobleza. Así, en

Toledo, el título de Alcalde Mayor pertenecerá a los ciuques de Maqueda; el de Alcalde de pastores de la Mesta a los marqueses de Montemayor; el de Alguacil Mayor a los condes de Fuensalida y el de Alcalde Mayor de Alzadas a los condes de Cifuentes.

\section{ABSTRACT}

The towns in Christian held territory on the Peninsula were independent at first. After the thirteenth century their magistratures came to be dominated by oligarchies formed of aristocrats and the upper middle classes, who kept these positions for themselves and monopolised their control. Subsequently the monarchy tried to dominate these town councils, taking advantage of any favourable circumstance to unify them under its control and Roman Law. This reduced the legal powers of magistrates as well as those of local codes of law. To this end the monarchs created a series of institutional positions (chief magistrate, alderman, appellate judge, judges...) and arrogated the right to name the holders of them. The members of certain aristocratic families were habitually named by the monarch to occupy these positions. Thus in Toledo the title of Chief Judge belonged to the Duke of Maqueda, while that of the Judge of the Shepherds of the Mesta belonged to the Marquis of Montemayor. The title of Chief Constable was at the disposal of the Counts of Fuensalida, and that of 
Los condes de Cifuentes tuvieron la potestad de nombrar un teniente que les representase y juzgase en su nombre; pero con la reforma de Juan II quedaron agregados a la jurisdicción real, recayendo su nom-

bramiento, por delegación, en el Corregidor correspondiente. Este hecho, unido a que el teniente era quien conocía en grado de apelación todas las causas civiles y criminales y pudiera revocar una sentencia dictada por aquél, provocaba cierta confusión jurisdiccional y un enfrentamiento institucional, por 10 que los corregidores se negaban o se resistian a su nombramiento, 10 que ocasionaba un proceso de protestas, súplicas, apelaciones y pleitos por parte de la ciudad a través del cabildo de jurados y un número idéntico de autos, provisiones y órdenes reales para que se efectuase el nombramiento y no se les removiese continuamente del cargo.

Esta situación perdurará hasta la desaparición del Antiguo Régimen y más concretamente hasta la ley de 28 de marzo de 1821, con la que se constituirán los Ayuntamientos Constitucionales.
Chief Appellate Judge belonged to the Counts of Cifuentes.

Although the Counts of Cifuentes had the right to name a representative to act as a judge in their name, this was abrogated by the monarchy. After the reform of Juan II the holder of this position was named, through delegation, by the corresponding chief magistrate. This, together with the fact that it was the representative who heard all civil and criminal cases in appeal, and that he was able to revoke the sentences of the chief magistrate, gave rise to a certain amount of confusion in jurisdiction. It also led to confrontation between institutions, so that those selected to be chief magistrates refused or resisted accepting the position. This in turn gave rise to a series of protests, petitions, appeals and lawsuits bought by the city through the council of jurors, together with an identical number of writs, provisions and royal orders to make selection take effect and prevent the position being held for short periods of time by different individuals.

This situation lasted until the end of the Old Regime, more specifically until the law of 28 March 1821, which created Constitutional Town Councils 
Desde el siglo XI a mediados del XII, en todo el territorio peninsular cristiano de realengo, excepto en Cataluña, donde seguían sometidos a la autoridad del señor, los municipios se constituirán en centros jurídicos, económicos, sociales y políticos autónomos. Se apoyarán para ello en milicias propias, en el poder judicial de los alcaldes, en sus propios recursos financieros y económicos (propios, industrias, servicios, multas, arbitrios, impuestos...), en los escasos intercambios comerciales y en la dificultad de los reyes para controlar un terreno más allá de un corto radio de acción por la escasez y el embarazo de las comunicaciones. Su gobierno y dirección evolucionará, sobre todo a partir del siglo XIII, desde el concejo abierto, como asamblea general de todos los vecinos, a la concentración del poder en manos de unos cuantos «hombres buenos" o caballeros, a causa del aumento de la población ciudadana, y con ello la imposibilidad de reunir a todo el vecindario para tomar decisiones comunitarias, y por la ambición de poder, control y mando de unos cuantos, que se aprovechaban de las benéficas consecuencias sociales y económicas que ello conllevaba.

Este proceso llevó de forma paulatina, pero inexorable, hacia formas de gobierno oligárquicas a partir de la segunda mitad del siglo XII, que se consolidarán en las dos siguientes centurias, al quedar reservadas las magistraturas municipales a los vecinos de origen hidalgo o burgueses poderosos (patriciado), es decir, personas poseedoras de un cierto nivel social y determinado patrimonio, que se reservan un papel predominante y monopolizan el gobierno del municipio, que pasa a ayuntamiento o regimiento de carácter restringido, reduciéndose la representatividad ciudadana y quedando anulado todo vestigio de participación popular. Esto será más fuerte y visible en las ciudades que tenían voto en Cortes debido a lo apetitoso y productivo que resultaba el cargo de Procurador (representante en Cortes).

Sobre estos cabildos, dominados por las clases sociales más adineradas, se van a lanzar los monarcas con el fin de controlarlos, dadas sus tendencias centralizadoras, sus anhelos de preeminencia soberana' y las aspiraciones de concentración del poder en sus manos, para someter y supeditar a sus dictados todo su reino en todos los ámbitos de la sociedad. A fin de conseguir sus propósitos, los monarcas aprovecharán cualquier coyuntura favorable, cualquier ocasión propicia que se les presente, apoyándose en su autoridad y en su actitud mediadora para resolver los conflictos que se originen y cuestionen en los municipios. En principio, los reyes eran requeridos por los que tenian problemas o en los que se suscitaban litigios, enfrentamientos o luchas por el poder y entonces enviaban a sus delegados para

Este vocablo es el que prefiere J. VICENS VIVES, mejor que «absolutismo" o "autoritarismo", para denominar las tendencias de los monarcas desde el medievo hasta el siglo XVII. Ver Coyuntura económica y reformismo burgués. Barcelona, 1974, p.112. 
que dilucidaran los conflictos, emitieran sus veredictos y dictaminaran sus sentencias. Esto fue aprovechado por los monarcas para introducir el Derecho Romano en todos los ordenamientos jurídicos de los municipios en detrimento de la competencia judicial de los alcaldes y de los fueros locales, uniformando a toda la sociedad contra la diversidad anterior.

El rey va a intervenir en la administración local ${ }^{2}$, con el fin de efectuar un mayor y mejor control sobre los municipios, y por ende sobre la nobleza, creando una serie de instituciones (corregidor, regidores, alcaldes de alzadas, merinos, merino mayor...) sobre los que se arroga el poder de nombramiento, al mismo tiempo que se conceden unos fueros a cada población (que propenden a uniformarse) por los que se regirán. Con ello se tiende a la práctica centralización mediante un aumento del intervencionismo real en estas ciudades anteriormente autónomas, a la vez que se mantiene una apariencia de autogobierno local. Todo este proceso conducirá al surgimiento del Esiado moderno.

\section{EL CASO SINGULAR DE TOLEDO}

Alfonso $\mathrm{VI}$ se encontró al tomar posesión de Toledo con tres grupos sociales diferenciados: musulmanes, judíos y mozárabes. Tres comunidades con diferencias de creencias y costumbres que, sin embargo, convivían en la ciudad. Tras la conquista de la antigua capital visigoda en 1085, se añadieron dos grupos más, los francos y los castellanos. Para recompensar a los que le ayudaron con eficacia en la toma de la ciudad, evitar la despoblación, mantener la personalidad de las distintas comunidades y la paz entre las mismas, concedió a esta ciudad tres fueros distintos: Fuero de los castellanos, de los francos y de los mozárabes. La situación civil y jurídica de los musulmanes (mudéjares) quedó establecida a través del pacto de pacificación. Sólo los judíos quedaron sin regulación escrita o pactada, permaneciendo bajo la protección del monarca. Los Fueros concedidos serían el preludio de otras concesiones que realizarán otros reyes posteriormente hasta la constitución definitiva del gobierno de Toledo en la primera mitad del siglo XV. El de los mozárabes fue otorgado el 19 de marzo de 1101. Los otros debieron serlo con anterioridad, pues en él ya se alude al de los castellanos ${ }^{3}$.

\footnotetext{
${ }^{2}$ Para una visión general acerca de este fenómeno ver LADERO, M. A., «El poder central y las ciudades en España, del siglo XIV al final del Antiguo Régimen", Revista de Administración Pública, XCIV (1981), pp. 173-198.

${ }^{3}$ Para todo lo relacionado con los fueros toledanos ver García Galio, A., "Los fueros de Tole do", en Anuario de Historia del Derecho Español, XLV, 1975; Garcia de Valdeaveyano, L., Curso de Historia de las Instituciones Española. De los orígenes al final de la Edad Medias. Madrid, 1986; BeneYto, J., Historia de la administración española e hispanoamericana. Madrid, 1958; Bretaño FERNÁNDEZ-PRIETO, J. M., "Aportaciones del Fuero Castellano y del Fuero Juzgo en la formación del Fuero de Toledo", en Anales Toledanos, XVI, 1983.
} 
El primero de estos fueros reconoce al pueblo el derecho de elegir sus propios alcaldes anualmente y además, el que los ciudadanos de sus colaciones o barrios nombrasen cuatro personas «de los más nobles y sabios" para que asistiesen con el juez a examinar los pleitos. El alcalde castellano se ajustará a las leyes del Fuero Viejo de Castilla.

A los francos se les concedió un merino y un sayón propios; si bien, no se conoce texto escrito que confirme la concesión de un fuero especial para este grupo social.

A los mozárabes se les dio un alcalde para lo civil, suprema autoridad gubernativa, administrativa y judicial, el cual decidiría en los pleitos internos y entre los de esta comunidad y los francos, con arreglo al Libro iudgo antiguo, Liber ludiciarum o Fuero Juzgo, mientras en lo criminal quedarian bajo las mismas leyes que los castellanos y la jurisdicción del alcalde de los nuevos pobladores ${ }^{4}$.

Cada uno de los alcaldes nombraba merinos menores y sayones (alguaciles), los cuales ejercían su jurisdicción como delegados de sus respectivos magistrados. A estos ministros había que añadir cuatro fieles, escogidos por los vecinos, para velar por los abastos y la policía; un capitán de guerra y varios alféreces que mandaban las fuerzas de la guarnición; y los alcaides que custodiaban, vigilaban y defendían las puertas, puentes y alcázar. Sobre todos estos magistrados municipales se hallaba el alcalde mayor, cargo de nombramiento real, quien además de ser el más alto dignatario de la ciudad, era juez ordinario en determinadas causas. Los alcaldes, que eran elegidos de entre las familias más ilustres y poderosas de la ciudad, ejercían su jurisdicción como jueces de alzadas, no sólo sobre Toledo capital, sino sobre todas las poblaciones del arzobispado que se regían por el fuero de Toledo. El alcalde mayor conocía de las apelaciones contra los fallos y sentencias de los anteriores.

Cuando el asunto era grave y concernía a todo el conjunto de la ciudad, se reunían los aicaldes castellano y mozárabe, a los que se podían unir el de los francos y los mílites o cabaileros de las distintas comunidades que lo deseasen, formando "Ayuntamiento", título que le otorgó Juan II por privilegio de 5 de mayo de $1423^{5}$.

Alfonso VII renovó los fueros a los toledanos (castellanos, francos y mozárabes) por un privilegio de fecha 16 de noviembre del año 1118 , que se

\footnotetext{
"Garcia Gallo, A,, “Los fueros...”, p. 424, 459-461; Martín Gamero, A., Historia de la ciudad de Toledo, Toledo, 1862, edición de 1979, documentos XIV (Fuero de Escalona, en el que se menciona y extracta ei de los castellanos de Toledo) y XVI (Fuero de los mozárabes); IzQUIERdo BeniTo, R., Privilegios reales otorgados a Toledo durante la Edad Media (1101-1494). Toledo, 1990, pp. 89-91.

martin Gamero, A., Historia de la ciudad..., p. 820; Arellano Garcia, M., “Breve historia del Ayuntamiento de Toledo" en Crónica Mozárabe, n. .19 , Marzo, 1987.
} 
conoce con el título de "Fuero General municipal de Toledo", mejorándolos considerablemente, como premio por los sacrificios y valor ejercidos en la defensa de la ciudad ante los ataques almohades ${ }^{6}$. El 24 de abril de 1136 este monarca confirma el de los francos ${ }^{7}$, y el 25 de marzo de 1155 el de los mozárabes, estableciendo el Fuero Juzgo como el único Derecho para todos los grupos sociales cristianos de la ciudad, aunque cada uno pudiera seguir disfrutando de sus propias prerrogativas ${ }^{8}$. Nuevas confirmaciones y concesiones se llevarían a cabo con los siguientes monarcas.

Con Alfonso VII y sus sucesores fueron introduciéndose alteraciones en las dignidades y oficios de gobierno de la ciudad, tanto en el ámbito judicial como en el económico. Con el Fuero General de Toledo se aumenta a diez el número de personas que ayudarán al alcalde mayor a administrar justicia, los cuales debían ser escogidos entre los "mejores", más "nobles" y más "sabios". Más tarde, este mismo rey creó los empleos de cuatro alcaldes mayores, de igual jurisdicción, para que juzgaran los pleitos; un alcalde mayor de alzadas, para que conociera de las apelaciones que se le elevasen; otro de los pastores para fallar lo referente a todos los asuntos ganaderos y pastoriles; un alguacil mayor; un alférez mayor y un alcaide de los reales alcázares. Todas estos cargos recayeron en las personas más notables de la ciudad, las cuales no los ejercian per se sino que nombraban unos sustitutos para su desempeño.

Fernando III y su hijo Alfonso $X$ volvieron a modificar la composición municipal. Añadieron seis fieles (tres del estado de los caballeros y tres del estado llano) para que velasen por los abastecimientos de la ciudad, una de las principales preocupaciones de los ayuntamientos en la época del Antiguo Régimen. Más adelante púsose al frente del Ayuntamiento, aunque sin facultad para tomar parte de sus deliberaciones, pero con suficiente autoridad como para dirigirle y controlarle procurando encauzar las decisiones de sus componentes hacia los intereses reales, un Adelantado o Asistente.

Desde sus inicios, el Ayuntamiento de Toledo fue abierto, es decir, en él tomaban parte con voz y voto todas las clases sociales; pero más tarde,

\footnotetext{
${ }^{6}$ Maftín Gamero, A., Historia de la ciudad..., en el $n .^{2}$ XVIl del Apéndice de ilustraciones y documentos, recoge la traducción hecha en la épeca de Fernando III. Este mismo autor en la p. 802 establece que para completar las lagunas existentes en este Fuero, se puede acudir al de Sevilla, dado por este mismo monarca en el año 1222, pues a lo largo de su redacción se acude a las siguientes expresiones: así como en Toledo; ansí como no son terludos los del barrio de Francos de Toledo; según fuero de Toledo o como los caballeros de Toledo. IzQUIERDo BENITO, R., Privilegios reales concedidos..., recoge la recopilación de los fueros de Toledo realizada por el propio Altonso VII, en p. 92 , además de una versión romanceada incompleta en p. 94, que se completa con la de p.116.

Maftín Gamero, A., Historia de la ciudad... lo recoge en el n. ${ }^{8} \mathrm{XV}$ del Apéndice de llustraciones y Documentos; IzQuierdo Benito, R., Privilegios reales concedidos..., privilegio n. ${ }^{0} 5$, p. 96.

Izouiendo Benito, R., Privilegios reales concedidos..., privilegio n. 8 p. 99 . Así lo interpreta Bretaño Fernandez-Prieto, J. M. a, "Aportaciones del fuero castellano... ", p. 13 y 15.
} 
con motivo de los escándalos y conflictos que frecuentemente se suscitaban en estas reuniones, juntas o asambleas, haciéndose tumultuarias y peligrosas, cuando el crecimiento de la población hizo poco menos que imposible la toma de decisiones comunes y por último, cuando la presión centralizadora de los monarcas se hizo más patente y agobiante, desapareció aquel espíritu democrático. El auge de la nobleza, en aumento constante desde las leyes protectoras y económicas de Alfonso X (la Mesta) llegó a su máxima expresión con los Trastámara, al apoyarse esta nueva dinastía en la aristocracia para alcanzar el poder y después tener que seguir concediéndole amplios privilegios para mantenerse en el trono.

En los primeros años del siglo XV, Fernando I de Antequera, actuando de tutor de su sobrino Juan II, impuso un sistema de gobierno municipal en varias ciudades castellanas, entre las cuales se hallaban Córdoba y Toledo, por medio de un ordenamiento de fecha 9 de marzo de 1411. Por él quitó el derecho de voto a los vecinos en los ayuntamientos. La forma de regimiento de Toledo quedó reducida a que caballeros y ciudadanos, cada dos años, eligieran cuatro compromisarios electores, quienes posteriormente elegían seis fieles mayores (tres de cada estado) que tenian que ser confirmados por el rey. Después, los cuatro electores, junto a los alcaldes, alguacil y los seis fieles, nombraban todos los cargos de los subalternos y dependientes del municipio; sin embargo sólo formaban el Ayuntamiento el alcalde mayor de la justicia, que lo presidía; el alcalde mayor ordinario; el alguacil mayor (todos ellos de nombramiento real) y los seis fieles elegidos, aunque se permitía la entrada de todos los caballeros que así lo quisiesen, los cuales tenían voz, pero no voto. Ahora aparecerá por primera vez el cargo de Procurador del Común, representante del poder popular perdido ${ }^{9}$. Como se puede observar, la oligarquización y el intento de control del gobierno local de Toledo y de otras ciudades importantes de la península por la Corona es innegable.

Este sistema no arraigó en la ciudad, al contrario, trajo inquietudes, enfrentamientos y desórdenes tanto en el momento de las elecciones como en el de la constitución del Ayuntamiento ${ }^{10}$, debido a las luchas por el poder entre las oligarquías urbanas, por lo que Juan II, por cédula de 10 de marzo de 1421, adoptó para Toledo el método establecido en Sevilla por Alfonso $X$ el Sabio, corregido por Alfonso XI. El Ayuntamiento quedó dividido en dos cuerpos principales: cabildo de regidores y de jurados. El primero

\footnotetext{
${ }^{9}$ Una copia, transcrita, del Ordenamiento dado a Toledo por el infante don Fernando de Antequera, se halla en SÁZZ SÁNCHEZ, E., "El libro del juramento del Ayuntamiento de Toledo", en Anuario de Historia del Derecho Español, 16, (1945), pp. 541-544. Y este mismo autor publicó "Ordenamiento dado a Toledo por el infante don Fernando de Antequera, tutor de Juan II, en 1411 ", en Anuario de Historia del Derecho Español, XV (1944), pp. 499-556.

${ }^{10}$ Alcocer, P., Hystoria o descripción de la Imperial Cibdad de Toledo. Toledo, 1554. f. |XXV| y Benito Ruano. E., Toledo en el siglo XV. Vida política. Madrid, 1961.
} 
estaba formado, en principio, por veinticuatro plazas divididas entre caballeros (dos tercios) y ciudadanos; pero de todos se requería la hidalguía. En general fue copado por los representantes de la nobleza media toledana. Era un cuerpo deliberante y con voto. El cabildo de jurados estaba formado, en sus inicios, por cuarenta y dos miembros, dos por cada parroquia latina de la ciudad. Eran elegidos por votación de los parroquianos. Pertenecían al común del pueblo. Tenían voz, mas no voto, en las decisiones municipales, pero fiscalizaban y moderaban la actuación de los regidores elevando su protesta en aquello que les pareciera que iba en contra del bien común o de la "República» y requiriendo que no se pusiera en ejecución, y si fuera necesario podian apelar al rey.

Los cargos de delegación regia eran el de Corregidor, creado por los Reyes Católicos en 1477, en sustitución del de Adelantado; el de Alcalde Mayor, el de Alcalde Mayor de Alzadas, los de Alguaciles Mayores y el de Alcalde de la Mesta o de los Pastores ${ }^{11}$. Estos cargos recaían en unas familias determinadas. Así, el de Alcalde Mayor era privativo de los duques de Maqueda; el de Alcalde de los pastores de la Mesta, de los marqueses de Montemayor; el de Alguacil Mayor, de los condes de Fuensalida y el de Alcalde de Alzadas, de los condes de Cifuentes ${ }^{12}$.

Este alcalde de alzadas ${ }^{13}$, que como hemos dicho, fue instituido por Alfonso VII para que conociese en grado de apelación de todas las causas civiles y criminales, revocando o confirmando en parte o en todo las que se juzgaran por el alcalde mayor, los cuatro alcaldes ordinarios y el alcalde de pastores, desde Juan II tenía el tercer lugar preeminente en el banco derecho. Este cargo, repetimos, se concedió a los condes de Cifuentes, con potestad de nombrar un teniente que gozaba de voz y voto para que les representase en el cargo y juzgase en su nombre. Pero con la reforma efectuada por Juan II, los tenientes quedaron agregados a la jurisdicción real. Es decir, se les mantuvo en sus poderes, pero el nombramiento debía efectuarlo el Corregidor, dejando a los propietarios sólo con el honor de dignidades del Ayuntamiento con voz y voto en él.

Para un mejor conocimiento de este tema, ver Santallana Bustillo, L., Gobierno político de los pueblos de España. Madrid, 1979. Edición y prólogo de Francisco Tomás y Valiente.

Para un conocimiento general de la evolución del sistema de gobierno de la ciudad desde Alfonso VI hasta ios Reyes Católicos, consultar Martín Gamero, A., Historia de la ciudad..., pp.793-833; Aranda Pérez, F.J., Poder y poderes en la ciudad de Toledo, Gobierno, Sociedad y Oligarquías en la Edad Moderna. Toledo, 1999, pp.40-55. Para conocer el eje del gobierno y administración en el Ayuntamiento de Toledo, es conveniente ver LORENTE TOLEDO, E., Gobierno y administración de la ciudad de Toledo y su término en la segunda mitad del siglo XVI. Talavera, 1982, pp.25-44.

A partir de este párrafo, la mayoría de los datos y circunstancias concernientes al tema que se trata en este artículo proceden de un Informe sobre la dignidad de Alcalde de Alzadas y nombramientos hechos desde su inicio por los señores corregidores, procedente del Archivo Municipal de Toledo (A.M.T.), Libro de Actas capitulares de 1701, n. ${ }^{2} 121$, ayuritamiento de 20-2-1702. 
Esta paradoja de que el teniente, es decir, el sustituto de la dignidad propietaria del cargo, por una parte sea designado por el corregidor y por otra decida en los juicios de apelación, le hace aparecer por encima de éste y provoca cierta confusión jurisdiccional; sin embargo, al deber el cargo al corregidor - representante real en la ciudad_, siempre se hallará bajo su órbita y dominio; pero en ocasiones la rebeldía o resistencia de aquellos hará que en algún momento los corregidores se nieguen a nombrarle, declarando que ellos eran suficientes para hacer justicia a la disminuida vecindad de Toledo. Esto acarreará un continuo proceso de protestas, súplicas, relaciones, apelaciones y pleitos por parte de la ciudad, a través del cabildo de jurados, y un número idéntico de autos, provisiones y órdenes reales para que se realice el nombramiento y mantenimiento en sus puestos a los alcaldes ordinarios y al alcalde mayor de alzadas. Ejemplo de ello es que el 27 de febrero de 1660 se dio auto para que se enviase una provisión real al corregidor don Diego Rubín de Celis, instándole a que cumpliese la carta ejecutoria ganada por el cabildo de jurados sobre el nombramiento de cuatro alcaldes ordinarios y un alcalde de alzadas. Dicha carta se envió con fecha 19 de marzo de dicho año. El corregidor se excusa diciendo que desde el primer día que se le requirió el privilegio de la ciudad de su corregidoría así lo ha hecho, pero que ahora no lo había ejecutado «por buscar personas de toda satisfacción y decentes». Entonces, en cumplimiento de la real provisión antedicha nombra rápidamente a tres, don Melchor de Noguera y Melón, don Miguel González de Córdoba y Marcelo de Villafane. A este úitimo no se le encuentra y por fin se averigua que reside es Madrid. El cabildo de jurados protesta que sólo se han nombrado a tres de los alcaldes ordinarios, que sólo el primero vive en Toledo y los otros dos no son vecinos de la ciudad, que los dos primeros, aunque han aceptado el cargo, por ser familiares del corregidor no han dado las fianzas ni hecho el juramento ante el Ayuntamiento, como es preceptivo, ni ejercen y que tampoco se ha nombrado alcalde de alzadas. El Consejo de Castilla ordena se envíe una segunda carta al corregidor con mayores penas y apercibimientos el 20 de octubre del mismo año ${ }^{14}$.

En otras ocasiones lo que se hace es iratar de perturbar e impedir que el alcalde de alzadas pueda cumplir con su oficio de juez de segunda instancia y así el cabildo de jurados de la ciudad gana una real provisión del Consejo, a 22 de enero de 1722, para que el corregidor, que a la sazón lo era el marqués de Olías, no "embarace ni perturbe" al alcalde mayor de alzadas su jurisdicción y pueda conocer de todas las causas civiles y criminales, juzgadas por ei corregidor o su alcalde mayor, en segunda instancia $^{15}$; y el 22 de marzo de 1735 se gana otra provisión real dada por el Consejo de Castilla, sobre que ni por el alcalde mayor ni ningún otro juez

\footnotetext{
${ }^{14}$ A.M.T., Archivo Secreto, caj. 2, leg. 2, n. ${ }^{\circ} 2$

A.M.T., Archivo Secreto, caj. 2 , leg.2, $n .^{\circ} 3$
} 
de la ciudad de Toledo se impidan las apelaciones que se interpongan ante el tribunal del juez de alzadas ni las diligencias hechas en su virtud. Se ordena que se cumpla la provisión antecedente de 22 de enero de $1722 .{ }^{16}$

El hecho de que los corregidores se negasen a nombrar alcalde de alzadas repercutía gravemente sobre el común de la ciudad que veía reducidos sus derechos de justicia al no poder apelar contra las decisiones tomadas por aquél, su teniente de corregidor o su alcalde mayor, aunque, a su vez, la existencia de este juez de segunda instancia reducía su autoridad, pues en muchos casos se revocaban las sentencias, en los asuntos civiles y criminales.

\section{HISTORIA SUCINTA DE LA DIGNIDAD DE ALCALDE MAYOR DE ALZADAS EN EL AYUNTAMIENTO DE TOLEDO Y SU CONFLICTIVIDAD}

En el siglo XVI, don Fernando de Silva, conde de Cifuentes, obtuvo de la reina doña Juana de Castilla, la merced de nombramiento de Alcalde de Alzadas del Ayuntamiento de Toledo, con fecha 13 de diciembre de 1512. El 15 de dicho mes y año se dio la posesión por poderes a través de Andrés Egas, persona en quien delegó para esta ceremonia, pero no consta que nombrase teniente.

El año de 1528 se suscitó un pleito, planteado por don Bernardo de Cárdenas, marqués de Elche, Alcalde Mayor de Toledo contra don Fernando de Silva y el Ayuntamiento, con motivo de la preeminencia en el asiento en el mismo entre estas dos dignidades. La Chancillería de Valladolid resolvió que el alcalde mayor fuera preferido al de alzadas y se sentase inmediato a la mano derecha del corregidor. Esta ejecutoria se vio en el Ayuntamiento el 7 de diciembre de dicho año y desde ese día se observó esta graduación de lugares.

El segundo alcalde de alzadas de la posesión de los condes de Cifuentes lo fue don Juan de Silva, Alférez Mayor de Castilla, nombrado por el emperador Carlos $V$ el 21 de diciembre de 1544 (nombramiento firmado en Madrid por el príncipe Felipe), por renuncia de su padre don Fernando. El citado nombramiento se hizo con la condición de que se presentase en el Ayuntamiento de Toledo en el término de sesenta días y de que no fuese clérigo de menores; y que si más tarde obtuviera tal ordenación, quedase vacante el oficio. El 12 de enero del siguiente año tomó posesión del cargo a través de Alonso Pérez de Rivadeneira. Tampoco consta que nombrase teniente.

\footnotetext{
A.M.T., Archivo Secreto, caj. 2, leg. 2, n. 4
} 
Por provisión del emperador Carlos $\mathrm{V}$ y firmada por el príncipe Maximiliano y su esposa, librada en Valladolid con fecha 20 de diciembre de 1548 , se nombró a Juan Duque de Estrada para el cargo por renunciación del anterior, con las mismas calidades despachadas en el real título anterior. Se especifica que en este nombramiento no habia habido venta ni cambio. EI juramento se le tomó el 2 de enero de 1549.

En el año 1551, don Juan de Silva, conde de Cifuentes, con fecha 20 de noviembre, fue nombrado para el cargo por renuncia de Juan Duque de Estrada, tomándosele juramento en el Ayuntamiento el 26 del mismo mes y año, no constando que nombrara teniente.

El quinto alcalde de alzadas de la citada familia lo fue don Fernando de Silva, a quien nombró Carlos $V$ el 25 de julio de 1556, en Bruselas, por fallecimiento de don Juan de Silva, su padre. Como el dicho don Fernando no tenía edad para ejercer el ministerio u oficio, se nombró para que lo usase y ejerciese hasta su mayoría de edad, a don Fernando de Silva, su tío. El juramento se efectuó en el Ayuntamiento el día 16 de octubre de dicho año.

En 1560 se presentó en el Ayuntamiento una real cédula de Felipe II librada en Toledo a 12 de agosto, por la que se prorrogaba por dos años el nombramiento anterior, no obstante haber cumplido la mayoría de edad don Fernando. El Ayuntamiento apeló contra esta prorrogación, pero con fecha 11 de septiembre del mismo año se recibió "sobrecarta" a favor de aquella, obedeciéndose y cumpliéndose como en ella se ordenaba. Por fin, en el año de 1564, don Fernando de Silva, conde de Cifuentes, tomó posesión de la alcaldía mayor de alzadas el 22 de marzo.

Don Juan de Silva presentó un real título de Felipe II, librado en Valladolid el 20 de diciembre de 1590, por el que se le concedía la alcaldía mayor de alzadas de Toledo, que se hallaba vacante por fallecimiento de su padre don Fernando, para que la tuviera de forma vitalicia; y por no tener mayoría de edad se nombró en su lugar hasta que aquel cumpliera los años correspondientes, a don Juan Gómez de Silva, su iutor. Este nombramiento se vio en el Ayuntamiento, en la sesión de 7 de febrero de 1591 y se le tomó juramento dos días después.

Al fallecer don Juan Gómez de Silva, actuó como tutor de don Juan de Silva, conde de Cifuentes, don Antonio de Herrera, el cual recibió una provisión de Felipe II para que sirviera en el cargo de alcalde de alzadas de Toledo hasta la mayoría de edad de aquél. Dicha provisión se vio en el Ayuntamiento el 23 de febrero de 1595 y el 25 se tomó el juramento al citado personaje. Por fin, el 4 de marzo de 1599, don Juan de Silva, al cumplir la edad que se requería para ejercer el cargo, pidió la posesión y uso de dicho oficio, recibiéndose el juramento y pleito de homenaje acostumbrado. 
No consta que los diferentes poseedores de la dignidad de alcalde de alzadas de Toledo nombrasen tenientes que les sustituyeran en el ejercicio directo del cargo, por lo que quedó dicha facultad en la regalía de los corregidores, los cuales actuaron de la siguiente manera:

Don Martín de Córdoba, Corregidor que fue recibido el año 1522, nombró al licenciado Francisco Téllez.

En el año 1525, don Juan Hurtado de Mendoza, que tomó posesión el 11 de octubre de dicho año, nombró al licenciado Castillo, licenciado Gutiérrez Vaca de la Palma, licenciado García y Bernardo de Orozco, sucesivamente.

El licenciado Pedro de Avilés, corregidor desde 1530, nombró al licenciado Meneses y a Alonso Martínez de Mora.

Don Pedro de Navarra, corregidor recibido en el año 1532, nombró al licenciado Meneses y al licenciado Pedro Téllez.

Don Gómez de Benavides, corregidor desde 1538, nombró al licenciado Francisco González de Cisneros y al doctor Rodríguez.

El licenciado Diego Ruiz de Lugo, que tomó posesión de la corregidoría el 6 de septiembre de 1546, nombró en su tiempo a los licenciados Francisco González de Cisneros y Ruiz Díaz, a Diego de Castroverde, y a los licenciados Vinar, Garcia de León y Téllez, sucesivamente.

Con motivo del desusado removimiento y nombramiento continuo de alcaldes de alzadas en ejercicio, el Ayuntamiento, por medio de sus procuradores en Cortes, acudió al Consejo de Castilla el año 1548 y pidió provisión para que el nombramiento que hiciera el corregidor no pudiese ser removido o revocado. Se consiguió una Orden Real de Carlos I y su madre, doña Juana de Castilla, fechada a 20 de junio de 1548, por la que se manda que el alcalde de alzadas no sea quitado ni removido del cargo sin preceder primero el mandato real, para que cesen los inconvenientes que se registraban en la administración de justicia ${ }^{17}$. Con fecha 30 de agosto del mismo año se emite otra provisión real, dada en Valladolid, donde especifica: «... os mandamos que despues que hubiéredes nombrado para que sea Alcalde de Alzadas, no lo removais ni quiteis y si tuvieredes causa justa para lo quitar envieis relacion a los del nuestro consejo y entre tanto y hasta que sea visto $y$ se os envie a mandar lo que en elio habeis de hacer, no le removais ni quiteis y no Agadez ende al pena de la nuestra merced...."

En 1710 , a 30 de junio, el rey, a requerimiento del cabildo de jurados, que habían presentado ante la Chancillería de Valladolid una petición de que no se removiese arbitrariamente al alcalde de alzadas de Toledo, des-

\footnotetext{
17. A.M.T., Archivo Secreto, carp. 2, leg. 2, n. 91

A.M.T., Archivo Secreto, caj. 2, leg. 2, n. ${ }^{9} 2$
} 
pachó una provisión real para que el alcalde mayor, don Francisco Gutiérrez de Castilla, ni por sí ni por sus ministros, no impidiese el uso de la jurisdicción del de alzadas ni la ejecución de los autos y sentencias por él emitidos, multando a dicho alcalde mayor al pago de veinte ducados y al corregidor, don Carlos Aragón y Borja, marqués de Cábrega, de otros veinte. Además, se ordena que se nombren para alcaldes de alzadas a personas sujetas a la jurisdicción real y que sean "hábiles y capaces para el uso y ejercicio del dicho oficio". Para dar cumplimiento a esta provisión real, el corregidor cesó a la persona que tenía nombrada, que era el doctor don Diego Ortiz de Susunaga, y en su lugar designó al licenciado don Juan Suárez de Zayas, a fin de que fuera persona sujeta a la jurisdicción real ${ }^{19}$.

En el Catastro de Ensenada ${ }^{20}$ se especifica que en el libro de Ordenanzas está inserto el siguiente punto: "Alcalde de Alzadas le nombra el corregidor $y$ antes de que use de su oficio se ha de presentar en el Ayuntamiento donde ha de hacer el juramento que de suso se contiene y dar fianzas de hacer residencia..., y que nombrado una vez por el corregidor no le puede quitar ni mudar si no diere causa legítima declarada por S. M. o por los señores de su Consejo, ni hacer el nombramiento entre tanto que nombre otro, sino llanamente". Más adelante se especifica que esta provisión fue dada en el año 1545 (sic) ${ }^{21}$ y que de ella hay sobrecarta litigada con el licenciado Lugo, corregidor y juez de residencia de Toledo.

De 1548 a 1559 tomaron posesión como corregidores de Toledo don Pedro de Córdoba, el licenciado López García de Castro, don Antonio de Fonseca, don Alonso de Córdoba, el licenciado Fernando Vello y don Gaspar de Peralta, marqués de Falces, sucesivamente. De todos ellos faltan los libros capitulares, pero en los expedientes de aquellos años consta que en el de 1559 , Fernando Vello nombró alcalde de alzadas al licenciado Meneses.

El 22 de febrero de 1564 se hizo cargo de la corregidoría don Fernando Carrillo, pero se halla en blanco su recibimiento, así como los restantes del Libro, por lo que no puede conocerse si hizo o no nombramiento, pues tampoco consta en los expedientes de aquel año.

Don Diego de Zúniga fue recibido como corregidor el 21 de junio de 1566 y no consta que hiciese nombramiento en el trienio que duró su mandato.

El año 1571 fue nombrado don Fernando Velásquez para el cargo de corregidor, pero falta el libro correspondiente a ese año y no sabemos nada de lo que tratamos.

19. A.T., Archivo Secreto, caj. 2, leg. 2, n. ${ }^{\circ} 2$

20. A.H.P.T., Catastro de Ensenada, H-695, punto 44

Esta fecha debe de ser un error del escribano, pues si se especifica que el corregidor era el licenciado Lugo, éste no entró en la corregidoría hasta el año 1546, además, como acabamos de ver, existe del documento expresado en la nota 18 . 
Don Juan Gutiérrez Tello fue recibido en el Ayuntamiento como corregidor el 14 de enero de 1573 y dos días después nombró como alcalde de alzadas al licenciado Marcos de Alarcón.

De 1579 a 1591 pasaron por Toledo como corregidores, el licenciado Torres Dávila, el licenciado Juan de Tejada, don Fadrique Portocarrero, don Francisco Carvajal y Perafán de Rivera. De todos ellos no hay libros capitulares. Por los expedientes pertenecientes a sus trienios, no consta que nombrasen alcalde de alzadas. Solamente en el libro de fianzas consta que don Fadrique Portocarrero nombró el 5 de agosto de 1579 por alcalde de alzadas al doctor Luis Belluga y el 24 del mismo mes al licenciado Diego Guillén Peraza. Por ausencia de éste, el 11 de noviembre de 1580 nombró al licenciado Juan Navarro y por haberse exonerado el licenciado Diego Guillén, el 9 de marzo del siguiente año nombró al licenciado Marcos de Alcocer. Don Francisco Carvajal nombró el 4 de junio de 1584 al licenciado Martín Alonso de Herrera y Perafán de Rivera, corregidor en el año 1589, nombró al licenciado Francisco de Madrid.

El licenciado Velarde fue recibido por corregidor de Toledo el 21 de junio de 1591 y en el ayuntamiento de 10 de julio nombró como alcalde de alzadas al licenciado Carrasco de Madrid.

El dos de junio de 1592 tomó posesión de su cargo de corregidor don Luis Fernández de Córdoba y en ese mismo ayuntamiento nombró al doctor Navarro como alcalde de alzadas interino, hasta la llegada del propietario.

Don Alonso de Cárcamo entró por corregidor de Toledo el 25 de junio de 1593 y en el mismo ayuntamiento nombró por alcalde de alzadas al licenciado Jurado, en el ínterin que libraba el propietario que había de venir. No se conoce si efectivamente llegaron los propietarios anteriormente aludidos, lo que sí se sabe es que continuó la interinidad hasta el nombramiento de nuevo corregidor.

Del año 1598, que está comprendido en el 1597, no hay libro. En este último año fue vuelto a nombrar corregidor de la capital don Francisco Carvajal y de los expedientes de su trienio no consta que nombrase a nadie.

En el año 1604 fue recibido nuevamente como corregidor don Alonso de Cárcamo, y por los expedientes de dicho año parece que en el ayuntamiento de 21 de junio nombró por alcalde de alzadas al licenciado Álvaro Ortiz de Zayas.

El 9 de abril de 1607 entró por corregidor don Francisco de Villacís y en el mismo ayuntamiento nombró al licenciado Rosales para el cargo de alcalde de alzadas.

Durante todo este período de tiempo que llevamos reseñado, que abarca exactamente un siglo (1512-1612), la dignidad de alcalde mayor de al- 
zadas había recaído en los condes de Cifuentes, aunque estos no lo habían ejercido efectivamente, sólo mantenían su empleo como miembros del Ayuntamiento con asiento y voto en él y con carácter honorífico y hereditario y no hicieron nunca contradicción en los nombramientos de alcaldes de alzadas por parte de los corregidores. El último poseedor de esta dignidad fue don Juan de Silva (1599) y desde él quedó suspensa la misma y por lo tanto vacante. Sin embargo, en cuanto a la acción judicial, los corregidores continuaron efectuando nombramientos como en épocas anteriores, constando hasta comienzos del siglo XVIII la siguiente relación:

El año 1612 (4 de junio), toma posesión de su cargo de corregidor don Diego de Zúñiga. En el mismo ayuntamiento nombró por alcalde de alzadas al licenciado Juan de Escobar de Barruelos.

En 1614, en la sesión del ayuntamiento de 10 de diciembre, don Juan Pérez de Zayas, alcalde de alzadas a la sazón, solicitó cédula de S.M. para que el que ejerciera esta jurisdicción cobrara un salario de 25.000 mrs. anuales de las "penas de Cámara". Se obtuvo la concesión por real cédula de 25 de octubre de este mismo año, dada en Lerma (Burgos) y refrendada por don Alonso Núñez de Valdivia.

El licenciado Gregorio López Madera fue recibido como corregidor en al ayuntamiento de 5 de agosto de 1615 y en el de 12 del mismo mes nombró como alcalde de alzadas al licenciado Bernabé Correa y Siruela.

D. García Carvajal entró por corregidor el 30 de abril de 1618 y en el ayuntamiento de 9 de mayo nombró al doctor Vázquez.

El corregidor don Diego Hurtado de Mendoza tomó posesión de su cargo el 31 de marzo de 1621, quien al parecer, y decimos "al parecer" porque no se ha hallado el nombramiento judicial, hizo recaer dicho nombramiento de alcalde de alzadas en el doctor Palomeque. El 8 de marzo de 1627 nombró, ante Ambrosio Mejía, escribano mayor, al doctor Fernández de Madrid, por ausencia del anterior.

Don Pedro Díaz Romero juró el cargo de corregidor de Toledo en su Ayuntamiento, el día 26 de mayo de 1628, no constando que durante su mandato efectuara nombramiento alguno. Lo mismo aconteció con su sucesor don Pedro Fernández de Velasco, corregidor de la ciudad desde el 16 de enero de 1631.

El 19 de diciembre de 1633 fue recibido como corregidor en el ayuntamiento toledano don Francisco Arévalo y Zuazo y el 30 de agosto del siguiente año, ante el escribano Juan Salcedo, nombró por alcalde de alzadas a don Bernabé de Tamayo, de modo interino, hasta la llegada del licenciado don Alonso de Montalvo, residente en Madrid, a quien tenía nombrado para este empleo. 
En 1639 recayó de nuevo el nombramiento en don Bernabé de Tamayo, aceptándosele como tal en el ayuntamiento de 17 de junio.

El 23 de marzo de 1641 entró como corregidor don Vicente Vañuelos, no constando que nombrase alcalde de alzadas en su tiempo; así como tampoco lo hizo don Iñigo de Córdoba, que tomó posesión de su cargo el 20 de noviembre del mismo año.

El 12 de junio de 1645 fue recibido como corregidor don Pedro Gómez de Cárdenas y el 27 de febrero del siguiente año nombró, ante el escribano Juan de Salcedo, por alcalde de alzadas, al licenciado don Jerónimo de Guevara, cuyo nombramiento se vio en el ayuntamiento del siguiente día, ante el que juró el cargo.

Don Bernardino de Meneses entró como corregidor el 17 de agosto de 1648 y don Alonso de Paz y Guzmán lo hizo el 10 de mayo de 1652, no constando que ninguno de los dos efectuase nombramiento de alcalde de alzadas. Por este motivo, el 14 de enero de 1653 el cabildo de jurados, a través de su representante, el jurado José Rodriguez, presentó un escrito al corregidor en el que decía: «que conforme a las ordenanzas de la dicha ciudad de Toledo, que estaban en uso y observancia de tiempo inmemorial a esta parte, en la dicha ciudad había de haber un alcalde de Alzadas, que conociese en grado de apelación de las causas civiles y criminales, que en primera instancia pasan ante la justicia ordinaria y cuatro alcaldes ordinarios para que con más facilidad fuesen despachados los negocios de los pobres de la República, cuyo nombramiento tocaba y pertenecian (sic) al dicho corregidor, como corregidor y justicia mayor de la dicha ciudad". Como no obtuvo respuesta satisfactoria presentó pleito y ganó una carta ejecutoria en la Real Chancillería de Valladolid, a 24-12-1655, para que los corregidores de la ciudad de Toledo usasen de la facultad que tenían de nombrar alcaldes de alzadas y cuatro alcaldes ordinarios ${ }^{22}$.

Don Martín de Arres y Girón, marqués de Casares, fue el siguiente corregidor, el cual nombró ante el escribano Sebastián López de la Cruz el 3 de febrero de 1656 al licenciado Francisco Francés Zorrilla, regidor de Toledo, quien juró en el ayuntamiento de 11 de febrero de dicho año.

El 29 de agosto de 1658 entró como corregidor don Diego Rubín de Celis Villafane y nombró el 10 de enero del siguiente año, ante el escribano Sebastián López, por alcalde de alzadas al licenciado don Gaspar Suárez de la Palma, el cual juró su cargo tres días después.

En las cuatro corregidorías siguientes, regidas por don Juan Vélez de Guevara, marqués de Quintana (8-8-1661); don Miguel Muñoz (24-12-1664);

${ }^{22}$ A.H.P.T., Gatastro de Ensenada, H-695, punto 44. 
don Francisco de Solier y Salcedo (22-8-1668) y don Luis Ramírez de Guzmán (19-2-1672), no consta nombramiento alguno.

El 1 de abril de 1675 fue recibido por corregidor don Francisco Barrados y Figueroa y el 23 de marzo del siguiente año nombró por alcalde de alzadas, ante el escribano Juan Gutiérrez de Celis, al licenciado don Gaspar Suárez de la Palma, el cual juró el cargo en el ayuntamiento de 21 de mayo de 1677.

Don Lorenzo Fernández de Villavicencio entró como corregidor de Toledo el 18 de julio de 1678 y el 12 de marzo de 1684 tomó posesión de dicho cargo don Francisco Miguel de Pueyo. No consta en los libros capitulares, ni en los expedientes de sus trienios, ni en el cuaderno de fianzas, que hiciesen nombramiento de alcalde de alzadas, y sólo se tiene noticia extraoficial que sirvió con ambos el oficio, el licenciado don Román de las Casas.

El 2 de mayo de 1689 fue recibido por corregidor don Francisco de Bargas y Lezama, y nombró ante el escribano mayor del Ayuntamiento, Eugenio de Valladolid, el 19 de julio de ese mismo año, como alcalde de alzadas, al licenciado don Gaspar Suárez de la Palma, el cual juró en el ayuntamiento de 20 de julio de ese mismo año.

Don Carlos Ramírez de Arellano y Navarra, conde de Murillo, que entró como corregidor el 26 de julio de 1692, no efectuó nombramiento durante su mandato.

El 13 de octubre de 1696, entró como corregidor don Martín Basurto de Sepúlveda y el 16 de noviembre del siguiente año nombró como por alcalde de alzadas, ante Manuel Ruiz Machuca, escribano mayor, a don Luis Dávila de Oviedo, quien juró su cargo en el ayuntamiento de 4 de diciembre de dicho año.

Don Alonso Pacheco fue nombrado corregidor de Toledo el año 1699 y designó al licenciado don Bernardo Borques, quien efectuó el juramento ante el Ayuntamiento, el 28 de septiembre del mismo año.

$Y$ es un siglo después de que quedara vacante esta dignidad en 1599 con su último poseedor, don Juan de Silva, cuando se recibe carta en el Ayuntamiento de Toledo, con fecha 2 de febrero de 1702, del actual conde de Cifuentes, quien notifica a este organismo que ha elevado un memorial al rey para que le otorgue la dignidad de Alcalde de Alzadas, que por tantos años poseyeron sus antecesores, pues él desea poseer el mismo honor. ${ }^{23}$ Es entonces cuando la imperial ciudad envía el informe con el historial completo de los nombramientos de alcaldes de alzadas desde el momento de ser otorgada la dignidad a los condes de Cifuentes, en el siglo

\footnotetext{
A.M.T., Libro de Actas n. ${ }^{23} 122$, ayuntamiento de 6-2-1702.
} 
XVI. Unos meses más tarde entra en el Ayuntamiento una cédula real firmada por la reina y refrendada por su secretario de Estado y Cámara de Castilla, don Nicolás de Castro, de fecha 26 de octubre, solicitando se envíe información sobre si en el conde de Cifuentes concurren las calidades que se requieren para capitular del Ayuntamiento de Toledo ${ }^{24}$. No obstante, ya, con fecha 8 de noviembre del citado año, una vez estudiado el citado informe por el Consejo de la Cámara Real, se había emitido el real título otorgando la dignidad de Alcalde de Alzadas de Toledo, con voz y voto de regicior a favor del conde de Cifuentes y de sus sucesores "en lugar de don Juan de Silva, su último poseedor, perpetuo por juro de heredad", y que le poseyera "con las demás preeminencias y asiento que tuvieron y gozaron vuestros antecesores y lo demás honorífico del empleo, según y como lo tuvieron por lo pasado, sin que por razón de tal alcalde de alzadas podáis tener y gozar otra cosa alguna", y todo ello "sin más facultad ni preeminencia que la del asiento con el voto activo y pasivo en él», y conociendo "que el teniente que así vos como los demás sucesores en la vuestra casa nombráredes le hayan de tener y servir con las mismas calidades y preeminencias como los propietarios si asistieran". Por fin ordena que se le reciba por el Ayuntamiento de Toledo y se le tome juramento de posesión "por lo que toca a lo honorífico". A la vez que la copia del título, se recibe un poder, otorgado por el conde a 12 de diciembre en Granada, a favor de don Alonso José de Madrid para que tome posesión en su nombre y él envía una carta desde la misma ciudad con fecha de 20 de dicho mes, expresando su deseo de que no se dilate su nombramiento se le confiera la dignidad alcanzada ${ }^{25}$.

Este título le supuso al conde un costo de $9.375 \mathrm{mrs}$. Esta misma cantidad deberían pagar todos los sucesivos herederos.

El regidor don Melchor José de Cisneros y el jurado don Gabriel Ángel Martín. comisionados por el Ayuntamiento, estudian la petición y el título otorgado al conde de Cifuentes, y emiten un informe en el que, entre otras cosas, dicen que «sólo pide el ejercicio de este empleo en la misma conformidad que le habian tenido sus antecesores y que estos lo gozaron ni tuvieron facultad de nombrar teniente dentro del Ayuntamiento cuando no le ejercieron los condes de Cifuentes por sus personas le sirvieron otros por renunciación..."; que este real título "se circunscribe sólo a conceder a dicho excmo. señor en su persona dicha dignidad sin facultad de nombrar teniente y aunque en la narrativa se expresa la voz teniente, somos del sentir, que ni es nueva gracia ni comprendida en la primitiva merced a que se refiere la que hoy se hace a dicho Sr. Conde, pero por si acaso su ex-

${ }^{24}$ A.M.T., Libro de Actas n. 122 , ayuntamiento de 6-2-1702.

25. A.M.T., Libro de Actas n. ${ }^{9} 123$, ayuntamiento de 8-1-1703. 
celencia quiere suscitar el derecho de nombrar teniente, deberá V. S., siendo servido mandarle dar la posesión de dicha dignidad de Alcalde Mayor de Alzadas a su excelencia protestando que por ello no sea visto asentir en la facultad de nombrar teniente para dentro del Ayuntamiento por ser merced de preeminencia acrecentada y deberá V. S., con el respeto debido, suplicar de ella para que en ningún tiempo le pase perjuicio con cuya protesta y súplica queda recibido el derecho de V. S. a cualquier acontecimiento". Visto por el pleno el precedente informe, se aprobó lo expresado en él y se mandó que se guardase lo que contenía y que se diese cédula de convite para el día siguiente a fin de dar posesión del oficio de Alcalde de Alzadas al conde de Cifuentes y en su nombre a don Álvaro José Fernández de Madrid, regidor de la ciudad de Toledo, lo cual así se hizo en presencia del escribano Cebrián Soriano.

Este panorama y el organigrama del Ayuntamiento persistirán hasta la desaparición del Antiguo Régimen, con el decreto de las Cortes de Cádiz de 23 de mayo de 1812, con el que se pretende acabar con el carácter vitalicio y hereditario de los cargos municipales y abrir las estructuras corporativas a una renovación de la composición de los Ayuntamientos; sin embargo este decreto no tendrá su aplicación efectiva hasta el Trienio $\mathrm{Li}$ beral (1820-1822), con la ley de 28 de marzo de 1821, que dispondrá la formación de los Ayuntamientos Constitucionales.

El autor

Fdo: Ángel Santos Vaquero 